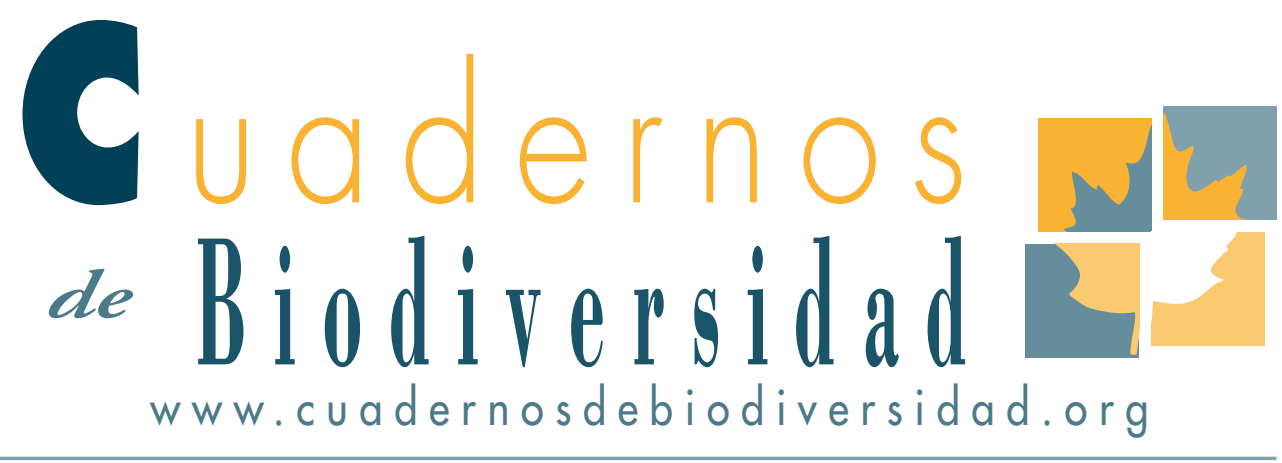

\title{
La ordenación de la Infraestructura Verde en el sudeste lbérico (Comunidad Valenciana, España)
}

\section{Ma Teresa Cantó López}

Universidad de Alicante, Aptdo. 03080, Campus de San Vicente del Raspeig, Alicante (EspaÑA). E-MAIL: TERESA.CANTO@UA.ES

\section{ABSTRACT}

The integration of urban space and adjoining rural areas need instruments to help maintain the value of natural capital and improve infrastructure support biodiversity. In this sense, the Green Infrastructure provides natural solutions to solve problems such as flood control, climate regulation of the city, pollination or water quality, and contributes to the economic, ecological and natural sectors of society. In Valencia (South Eastern Spain), Law 4/2004 of 30 June, spatial planning and landscape protection (LOTPP) adds Article 19a called green infrastructure as a network of spaces formed by territorial areas and elements of high environmental, cultural and visual value that integrates and determines the territorial and municipal planning.

\section{KEY WORDS:}

Regional planning, Green Infraestructure, Landscape, Urban planning, Biodiversity.

\section{INTRODUCCIÓN}

Desde hace varias décadas, el urbanismo, la ordenación del territorio y la protección del paisaje se enfrentan a un reto común: la integración del espacio rural y urbano. En esta tarea, la planificación urbanística y el derecho diseñan técnicas e instrumentos que desarrollan actuaciones para unificar ambos espacios, bien sean en el borde de las ciudades o en las edificaciones del espacio rural insertadas en el paisaje. Hay que señalar que la eficacia de las medidas 
adoptadas es todavía insuficiente para la configuración del espacio natural, rural y urbano integrado, propuesto por la Cátedra Unesco de Reservas de la Biosfera y Ambiente Urbano.

En este sentido, la Agenda Territorial de la Unión Europea 2020 (Agencia Territorial de la Unión Europea 2020: Hacia una sociedad integradora, inteligente y sostenible para una Europa de Regiones diversas, de 18 de mayo de 2011, Hungría) conocedora de los desafíos del cambio climático, la pérdida de biodiversidad y la vulnerabilidad de los paisajes, propone el desarrollo integrado de las ciudades y zonas rurales mejorando su accesibilidad y capacidad local mediante la utilización y salvaguarda de sus valores naturales, funciones ecológicas y servicios. En cuanto a la gestión y la conexión de los valores ecológicos, paisajísticos y culturales de las regiones, se promueve la integración de los sistemas ecológicos y las zonas protegidas por sus valores naturales en las redes de infraestructura verde en todos los niveles.

En este contexto, la ley valenciana 4/2004, de 30 de junio, de ordenación del territorio y protección del paisaje (LOTPP) introduce en su artículo 19 bis la denominada Infraestructura verde como una red de espacios formada por áreas y elementos territoriales de alto valor ambiental, cultural y visual.
A escala municipal, esta red de espacios se va a convertir en un elemento de ordenación estructural y pormenorizada en el planeamiento municipal según el anteproyecto de ley valenciana de ordenación del territorio, urbanismo y paisaje en trámite de aprobación, implicando a nivel local que los municipios establezcan la infraestructura verde como elemento de planeamiento (anillo verde, actuaciones en fachadas, parques) que va a ser un activo para la ordenación urbanística del municipio y del paisaje.

La Infraestructura verde (Figura 1) se configura como un activo esencial de desarrollo sostenible en la ordenación territorial que pone en valor el componente ambiental del territorio en la planificación y en el crecimiento de las demandas de uso de suelo para usos y actividades residenciales, dotacionales o productivas, desde el principio de desarrollo territorial y urbano sostenible. Así, en el presente trabajo se analizan las características de la planificación de la Infraestructura Verde en el ordenamiento valenciano.

\section{¿QUÉ ES LA INFRAESTRUCTURA VERDE?}

La Infraestructura Verde es una red estratégicamente gestionada y planificada de la que depende la
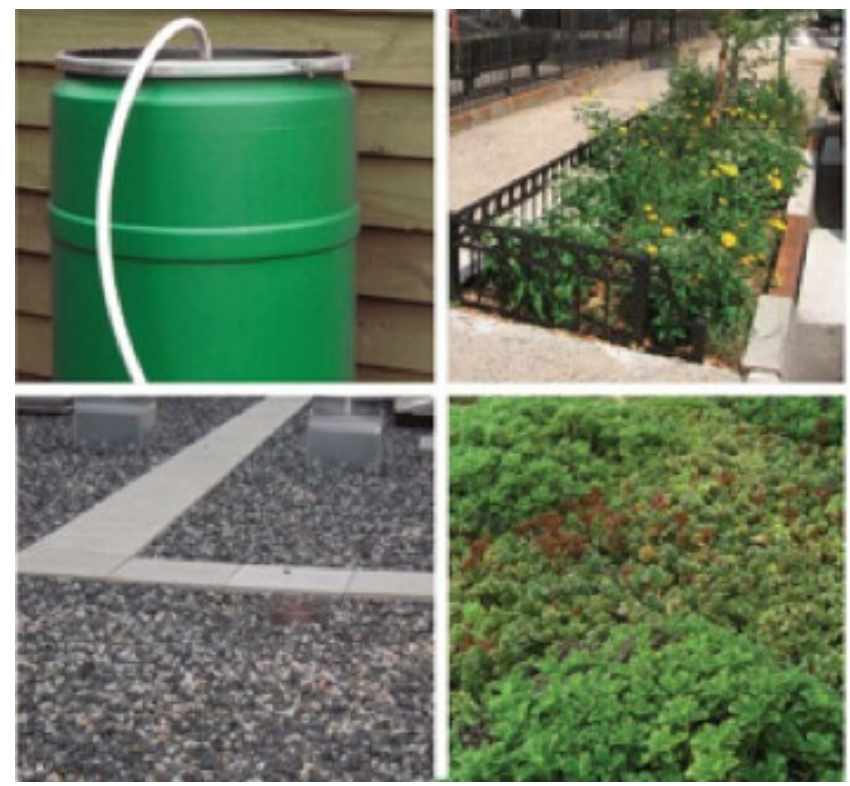
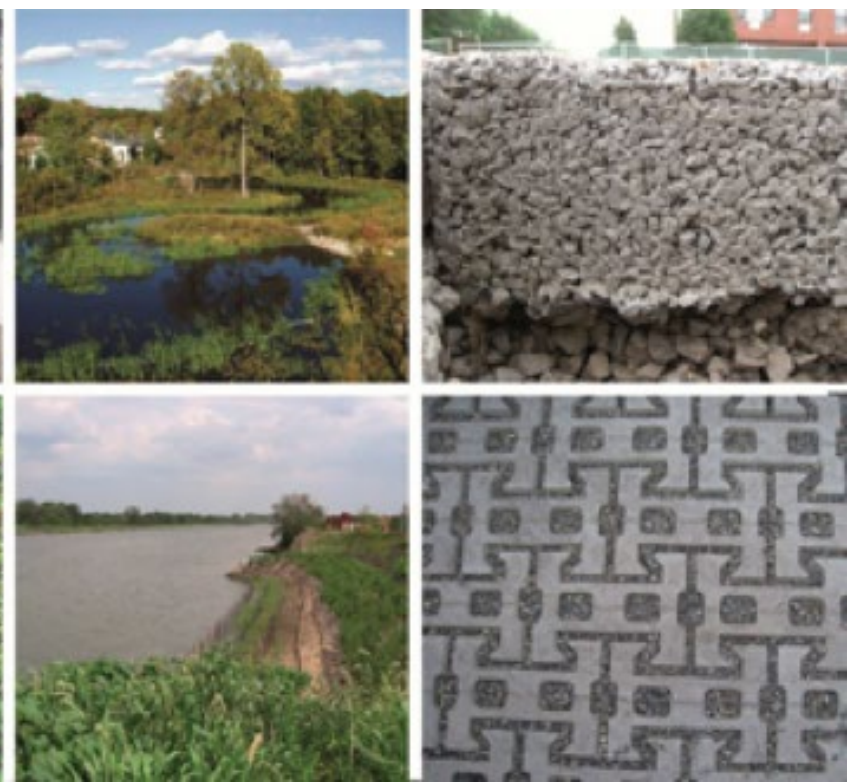

Figura 1. GI NY. Diferentes elementos de Infraestructura Verde urbana y regional 
permanencia y el crecimiento de una comunidad, ya que se trata de una estrategia de conservación de determinados espacios esenciales para el mantenimiento del funcionamiento ecológico saludable. Así, Benedict y Mcmahon (2002) definen la infraestructura verde como "una red (sistema de soporte de vida natural) interconectada de los cursos de agua, humedales, bosques, hábitats de vida silvestre, y otras áreas naturales; vías verdes, parques y otras tierras de conservación; granjas de trabajo, ranchos y bosques; desierto y otros espacios abiertos que apoyar a las especies nativas, mantener los procesos ecológicos, mantener el aire y los recursos hídricos y contribuir a la salud y la calidad de vida de las comunidades y los pueblos de América” .

Aunque el término de "infraestructura verde" aparece en la década de los noventa, su concepción americana tiene sus raíces en los siglos XVIII y XIX, derivada de dos ideas fundamentales: la idea de que los parques unen espacios verdes para el beneficio de las personas y la idea de la preservación de las áreas naturales en beneficio de las personas y en la lucha contra la fragmentación del hábitat (Firehock, 2010). El arquitecto paisajista F. Law Olmsted en su trabajo sobre los parques públicos, ideó un sistema de parques desde Nueva York hasta San Francisco, en el que los parques quedan vinculados entre sí o rodean barrios enteros proporcionando efectos positivos para las personas (por ejemplo, con un enfoque en la recreación, senderos para bicicletas y peatones y mejora de la salud pública). No obstante, el término infraestructura verde se ha utilizado confusamente en relación con la "construcción verde" o con la construcción de infraestructuras (raingardens) para gestionar los efectos de las inundaciones debido a las aguas pluviales en la ciudad con el aumento del uso de la vegetación, (http://water.epa.gov/infrastructure/greeninfrastructure/index.cfm). Después, se han ido incorporando programas o proyectos multifuncionales de espacios para la disminución de la contaminación atmosférica y mejora de la biodiversidad urbana con repercusión económica, ambiental y laboral para la comunidad, en colaboración con agentes públicos locales, privados, empresas o particulares (Taylor y Taylor, 2013).
En el ámbito comunitario, la Estrategia de la UE sobre la Biodiversidad [COM (2011) 244 final] de 2011 señala como objetivo el mantenimiento y mejora de ecosistemas y servicios ecosistémicos en 2020 mediante la creación de infraestructuras verdes y la restauración de ecosistemas degradados. Este documento subraya la importancia de la infraestructura verde y en su actuación 6 fija las prioridades de restauración y el fomento del uso de la infraestructura verde, así como el uso de incentivos para los proyectos y el mantenimiento de servicios ecosistémicos (entendiendo por tales los beneficios que aporta la naturaleza como alimentos, materiales, agua limpia, aire puro, regulación climática o lugares de recreo).

A escala europea, la Infraestructura Verde es una herramienta multifuncional que aporta servicios ecológicos, económicos y sociales mediante soluciones naturales a las personas. Así se define en la Comunicación de la comisión Europea sobre Infraestructura Verde: mejora del capital natural de Europa [COM (2013) 249 final] como "una red de zonas naturales y seminaturales y de otros elementos ambientales, planificada de forma estratégica, diseñada y gestionada para la prestación de una extensa gama de servicios ecosistémicos. Incorpora espacios verdes (o azules, en el caso de ecosistemas acuáticos) y otros elementos físicos de espacios terrestres (incluidas las zonas costeras) y marinos. En los espacios terrestres, la infraestructura verde está presente en los entornos rurales y urbanos".

Esta estrategia de conservación opera primero a escala de paisaje, y se fija idealmente, antes de que comience el desarrollo, después se integra a escala local, donde los enfoques de la infraestructura verde se centra en los árboles de las ciudad, los hábitats y los arroyos, los parques, los senderos, y más recientemente los suelos de buena calidad y las oportunidades de restauración del suelo, por ejemplo en los solares vacantes.

De acuerdo con esta concepción, la infraestructura verde se define como un instrumento multifuncional que aporta servicios ecológicos, económicos 
y sociales a la sociedad mediante la conservación de una red interconectada de espacios, esenciales para el mantenimiento del funcionamiento de los recursos naturales que hacen posible la vida en el territorio. En su identificación, diseño y conservación de la red es fundamental el concurso de varias disciplinas como la planificación, la arquitectura del paisaje, la ecología, la biología de la conservación, la silvicultura o el transporte.

\section{CONCEPTO DE INFRAESTRUCTURA VER- DE EN LA LOTPP}

De acuerdo con la estrategia europea, la infraestructura verde, se convierte en un elemento normalizado de la ordenación del territorio y del desarrollo territorial, partícipe de la aplicación de las políticas territoriales y sectoriales (transporte, energía, agricultura, diseño de las ciudades...). Una vez fijada la estrategia comunitaria, la infraestructura verde se desarrolla en España a escala nacional, regional (autonómica) y local. A nivel nacional deben estipularse las mejoras prácticas y establecer un marco de actuación en educación, comunicación y participación. Sin embargo, son las legislaciones autonómicas en materia de ordenación del territorio aquellas que reconocen la infraestructura verde a nivel regional. En la Comunidad Valenciana, con el fin de lograr el objetivo de la calidad de vida y desarrollo sostenible, la preservación de la biodiversidad y el mantenimiento de los recursos ecológicos se introduce esta figura en el art. 19 bis LOTPP. Se define como "la estructura territorial básica formada por las áreas y elementos territoriales de alto valor ambiental, cultural y visual, por las áreas críticas del territorio que deban quedar libres de urbanización; y el entramado territorial de corredores ecológicos y conexiones funcionales que pongan en relación a los elementos anteriores". Como señala la norma, se trata de una metodología de aproximación al territorio de carácter vertebrador y continuo que abarca desde la escala regional a la urbana y cuya caracterización y diseño debe ser previo a la planificación del suelo. En todo caso, por determinación legal, se relacionan una serie de elementos en los que se incorporan tanto los espacios de mayor valor ambiental, paisajístico y cultural como los espacios críticos susceptibles de riesgos naturales e inducidos: formando una red continua de elementos de conexión biológica y territorial que logran la permeabilidad del sistema y contribuyen a mejorar la diversidad biológica global del territorio. El régimen jurídico aplicable a los espacios incluidos en la red y las reglas de compatibilidad de usos será determinado por la legislación específica de protección y por los planes urbanísticos y territoriales que los delimiten. En este sentido, la planificación de la infraestructura verde corresponde al Consell mediante la elaboración de un Plan de Acción Territorial.

Merece la pena destacar que en breve se reforzará en la Comunidad Valenciana el marco normativo de este instrumento con la aprobación del Proyecto de ley de la Generalitat, de Ordenación del Territorio, Urbanismo y Paisaje de la Comunidad Valenciana (BOC 241, de 16.05.2014, en adelante, LOTUP), que introduce algunas novedades, como es planificación y gestión a escala municipal de la infraestructura verde. En general, se mantienen las características principales determinadas en la legislación anterior. En la Exposición de Motivos se insiste en su característica principal como "una red interconectada de los espacios de mayor valor ambiental, paisajístico y cultural". A continuación, desde un punto de vista conceptual, se aborda la Infraestructura Verde como "una nueva metodología de aproximación a la realidad territorial, que incluye los terrenos con mayores valores del territorio y, al igual que las infraestructuras tradicionales, tales como carreteras, vías férreas, etc., vertebra el territorio y le dota de continuidad". También hay que destacar su delimitación previa a la planificación de los nuevos crecimientos urbanísticos así como su alcance a todas las escalas del territorio.

En este sentido, el proyecto refuerza este concepto tanto en la regulación de su objeto y contenido en el capítulo I del Titulo I, como en su carácter multifuncional (art. 4.5 LOTUP) orientado a vertebrar el territorio mediante itinerarios que propicien la mejora de la calidad de vida de las personas, sobre 
todo en las áreas urbanas y en el medio rural, y fomentar una ordenación sostenible del medio ambiente urbano, preservando la vinculación entre los espacios y los servicios que aportan a las personas, presentes desde su origen en la infraestructura verde. Sin embargo, como advierte Taylor y Taylor (2013) hay una ausencia de mecanismos para detectar y evaluar las posibles externalidades negativas de esta infraestructura y sus consecuencias en los espacios urbanos, ya que son aspectos a tomar en cuenta en la toma de decisiones en la planificación y gestión de la red (especies invasoras, propagación de los alérgenos o toxinas en las plantas, los animales de vida silvestre que transmiten enfermedades, daños a la infraestructura construida por descomposición o raíces de los árboles, el agotamiento de los recursos hídricos debido a la riego, el escurrimiento de nutrientes o la propagación de contaminantes a través del suelo y material vegetal).

Igualmente, el art. 5 LOTUP establece los espacios que integran la infraestructura verde, $y$ que son aquellos elementos que desempeñan una función ambiental y territorial, incluyendo espacios protegidos por una regulación específica y otros que carecen de esa cualidad. En cualquier caso, los usos $\mathrm{y}$ aprovechamientos han de ser compatibles con el mantenimiento de la estructura y funcionalidad de la red. De esta lista exhaustiva forman parte espacios protegidos como: a) La red de espacios que integran Natura 2000 en la Comunitat Valenciana, y los espacios naturales protegidos declarados como tales de conformidad con la Ley 11/1994, de 27 de diciembre, de Espacios Naturales Protegidos de la Comunitat Valenciana, b) Las áreas protegidas por instrumentos internacionales en la Ley 42/2007, de 13 de diciembre, del Patrimonio Natural y la Biodiversidad, c) los ecosistemas húmedos y masas de aguas, continentales y superficiales como los espacios adyacentes que contribuyan a formar paisajes de alto valor, d) los montes de Dominio Público y de Utilidad Pública o Protectores que se encuentren incluidos en el correspondiente Catálogo, así como los terrenos que sean clasificados como Áreas de Suelo Forestal de Protección, e) Las zonas críticas por riesgos naturales o que se encuentren sometidas a riesgo de inundación, de acuerdo con lo establecido en la normativa valenciana. También espacios no protegidos como: a) los espacios de la zona marina y costeros de interés ambiental y cultural recogidos en la normativa territorial, b), las áreas que el planeamiento territorial, ambiental y urbanístico, en desarrollo de la presente Ley y de las respectivas normativas sectoriales, establezca explícitamente como adecuadas para su incorporación a la mencionada Infraestructura Verde, por su interés para la conservación del paisaje, para la protección de terrenos que presenten especiales valores agrarios cuya preservación sea conveniente para el medio rural, o para la protección de espacios naturales que, sin haber sido declarados expresamente como protegidos, reúnan valores naturales merecedores de protección o se hallen profundamente transformados, en los que sea necesario establecer medidas de rehabilitación destinadas a disminuir los impactos paisajísticos existentes. En el art. 5.2 h) LOTUP introduce expresamente las áreas agrícolas como espacios de la infraestructura verde cuando, por su elevada capacidad agrológica, funcionalidad respecto de los riesgos del territorio, genere un paisaje cultural característico de la Comunidad Valenciana, o sea soporte de productos agropecuarios de excelencia, y sean adecuadas para su incorporación a la Infraestructura Verde y así lo establezca la planificación territorial, urbanística o sectorial. Y por último, ámbitos que garanticen la adecuada conectividad territorial entre los elementos constitutivos de la infraestructura verde, con especial referencia a las áreas fluviales, vías pecuarias, afecciones y los conectores ecológicos.

Por otra parte, y a diferencia de la regulación por la LOTPP, el art. 5.3 LOTUP ha previsto los mecanismos de incorporación a la Infraestructura Verde previamente delimitada. Así, los nuevos espacios que cuenten con una regulación ambiental, cultural o sectorial específica se añaden por el acto de declaración, catalogación o aprobación del instrumento que los regule. Los espacios restantes se incorporan por la aprobación del instrumento de planeamiento territorial o municipal, y si posteriormente se excluyen del mismo debe ser objeto de justificación detallada. La planificación de la infraestructura verde se extenderá a los suelos urbanos y urbanizables, comprendiendo 
los espacios libres y zonas verdes públicas relevantes junto con los itinerarios que permitan su conexión.

A diferencia de la LOTPP, la infraestructura verde se delimitará a nivel municipal mediante los instrumentos urbanísticos municipales bajo la supervisión de la administración autonómica en relación con su coherencia y funcionalidad. La LOTUP prevé que "La identificación y caracterización de los espacios que componen la Infraestructura Verde de la Comunidad Valenciana se realizará en los instrumentos de planificación territorial y urbanística a escala regional, supramunicipal, municipal y urbana, siendo la Conselleria competente en materia de ordenación del territorio y paisaje la encargada de supervisar su adecuada coherencia y funcionalidad". Además, cabe destacar que su exclusión en revisiones o modificaciones posteriores del planeamiento, deberá ser objeto de una justificación detallada.

\section{LA INFRAESTRUCTURA VERDE EN LOS INSTRUMENTOS DE PLANIFICACIÓN TERRITORIAL.}

A nivel autonómico, la Infraestructura Verde del territorio constituye el tercer eje de la Estrategia Territorial de la Comunidad Valenciana (ETCV) aprobada por el Decreto 1/2011, de 13 de enero del Consell. Para la ETCV, el territorio es un recurso limitado que desde un punto de vista funcional actúa como soporte para el mantenimiento de los ecosistemas y como portador de valores ambientales y culturales, siendo el paisaje la estructura perceptiva del mismo. La Infraestructura Verde se entiende como un sistema de gestión de espacios abiertos integral que puede contener tanto elementos urbanos como elementos para conectar los espacios verdes de las ciudades con las de su entorno rural; todos ellos deben formar una red continua en el territorio, y en consecuencia se fijan una serie de directrices y criterios para la planificación y gestión de los espacios. El título III de la ETCV (Directrices 37 a 40, y 48 a 49) insiste en su finalidad de mejora de la calidad de vida de los ciudadanos y en su función orientadora de los futuros desarrollos ya que su ámbito de actuación ha de estar delimi- tado con anterioridad al diseño de las actuaciones transformadoras del territorio. Especialmente, y en relación con la integración de las zonas urbanas y rurales, se introducen entre los principios directores de actuaciones territoriales en materia de paisaje, la incorporación de objetivos de calidad de los nuevos bordes urbanos procurando la transición entre el paisaje de la ciudad y su entorno. Con este objetivo, se establece la necesidad de propiciar una estructura urbana adecuada, definiendo espacios de transición, los bordes urbanos y su silueta, atendiendo a cada una de sus particularidades. Igualmente, las actuaciones territoriales deberán preservar las vistas hacia los paisajes de mayor valor y favorecer su acceso y disfrute en un marco de movilidad sostenible.

No obstante, la infraestructura verde a escala autonómica se define en el Plan de Acción Territorial de la Infraestructura Verde y el Paisaje en la Comunidad Valenciana (Figura 2). Este instrumento permite caracterizar los espacios que forman la red y los paisajes más relevantes del territorio. El paisaje se convierte en un elemento condicionante de la ordenación territorial, la planificación urbanística municipal, en consecuencia, deberá respetar e incluir en la infraestructura verde local las áreas identificadas en el marco de una estrategia que enlaza, conecta e integra ambos niveles. Este Plan contiene una serie de acciones que se desarrollarán para facilitar la transición entre el paisaje urbano y rural. Por ejemplo, la delimitación de recorridos escénicos y de las zonas de afección visual desde las redes de comunicación. Una vez aprobado, las administraciones públicas implicadas quedan vinculadas a realizar las actuaciones precisas sobre los objetivos de la infraestructura verde, pues se establecen los criterios y directrices para la elaboración de Estudios de Paisaje y de Integración Paisajística, en relación con: la mejora visual de los accesos a los núcleos urbanos y de las áreas de actividad económica, la protección de las vistas desde los principales recorridos y las vistas más valiosas.

Además, otras figuras como los programas de paisaje que acompañan a los estudios de paisaje o estudios de integración paisajística, tienen por objeto concretar actuaciones para la preservación y puesta 


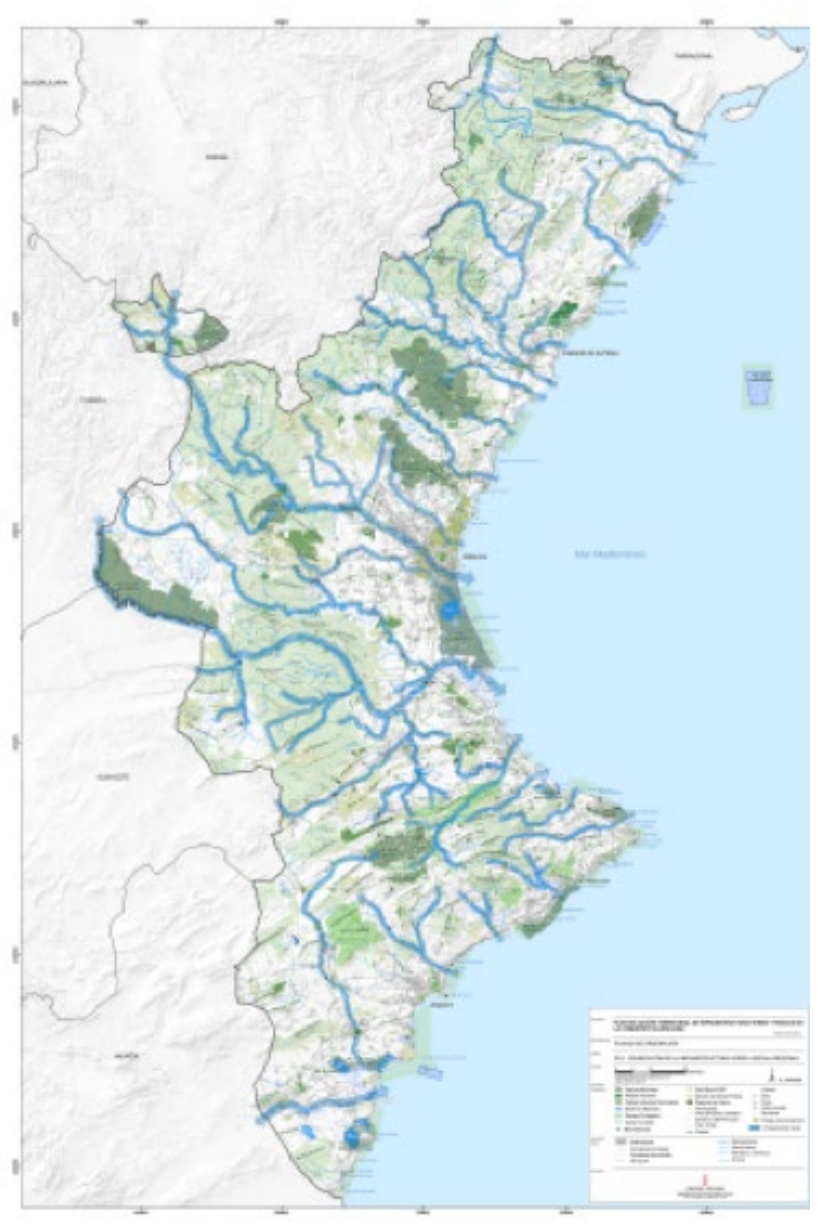

Figura 2. Plan de Acción Territorial de la Infraestructura Verde y del paisaje en la Comunidad Valenciana.

en valor de los paisajes y la articulación armónica de aquellos, con atención particular hacia los espacios de contacto entre los ámbitos rural y urbano o la mejora paisajística de los entornos rurales.

Por último, la LOTPP incluye una serie de normas de integración del paisaje urbano en el planeamiento municipal vinculadas al objetivo territorial de la mejora de la calidad de vida, en la mejora del entorno urbano y su incidencia sobre el paisaje. En esta mejora, la administración debe intervenir mediante obras vinculadas a la integración del paisaje periférico en la ciudad articulando la transición con el entorno natural. Los estudios de paisaje incluidos en el planeamiento, van a definir en el borde urbano las tipologías edificatorias adecuadas al entorno, potenciando las perspectivas y vistas del núcleo urbano, resaltando los elementos valiosos del entorno en la escena urbana y la visualización desde los espacios construidos.

En el modelo de la ciudad ambiental, se debe procurar la integración del paisaje periférico en la ciudad mediante la incidencia en el borde urbano, la definición de tipologías edificatorias, o destacar elementos valiosos de la escena urbana. A fin de mejorar el entorno urbano y su aspecto de impacto visual, la Administración autonómica y local tienen la obligación de elaborar criterios, instrucciones o medidas normativas aptas para la adopción de disposiciones jurídicas vinculantes en materia de estética en las ciudades, que aporten criterios objetivos de adecuación de las construcciones a los parámetros edificatorios, tanto en zonas de marcado interés cultural o arquitectónico como en urbanizaciones de nueva planta, o en las distintas partes de la ciudad, de modo que si las infraestructuras logran un nuevo equilibrio o armonía paisajística, no tienen motivo para deteriorar la estética urbana (Fernández Rodriguez, 2013). El art. 35 LOTPP establece normas de aplicación en relación con el paisaje urbano y que se incorporan al art. 8 LOTUP como criterios generales para la integración paisajística. En particular, dispone que el planeamiento municipal ha de propiciar una estructura urbana adecuada para lograr la integración de los núcleos de población en el paisaje, definición de bordes urbanos, silueta y accesos desde las principales vías de comunicación, incorporando criterios estéticos (Fernández Rodriguez, 2007). En esta línea, los programas de imagen urbana en áreas predefinidas en el planeamiento tienen como finalidad mejorar la calidad y el atractivo de los espacios más emblemáticos de los cascos urbanos y de su entorno inmediato. Los Programas de imagen urbana tienen el siguiente contenido: secuencia visual de los accesos al núcleo urbano, la silueta urbana, hitos, rasgo volumétrico y cromatismo de la edificación, la formalización de un borde entre la zona edificada del casco urbano y campo abierto, la puesta en valor de elementos del núcleo urbano, la conexión de un sistema de espacios públicos abiertos, conexión de viario, zonas verdes, recorridos peatonales y la seguridad peatonal y comodidad para el uso de espacios públicos mediante pavimentos, mobiliario urbano, plantación de árboles y paseos 
peatonales. Así, se reconoce que el diseño de los espacios públicos y el viario han de garantizar la funcionalidad de la infraestructura verde y el mantenimiento de las vistas y perspectivas que lo caracterizan. En este sentido, hay que destacar el art. 12 LOTUP dedicado a la mejora de la calidad de vida en las ciudades porque recoge los postulados de la arquitectura del paisaje al establecer expresamente que "los nuevos espacios públicos, o su reforma, deben configurar la imagen urbana como el resultado de un proyecto unitario, coherente y articulado por la infraestructura verde urbana y la red de espacios dotacionales". En ningún caso, los espacios públicos pueden conformarse como mero resultado residual e inconexo de las implantaciones privadas", declarando así la vinculación entre los espacios públicos interconectados y la calidad de vida en la ciudad.

\section{LA DELIMITACIÓN DE LA INFRAESTRUCTURA VERDE LOCAL}

Hay que tener en cuenta que la infraestructura verde reviste especial importancia en el entorno urbano, pues sus elementos aportan mejoras para la salud, la calidad del agua o del aire en la ciudad. Por ejemplo, utilizar la infraestructura verde en un entorno urbano, incorporando parques ricos en biodiversidad, espacios verdes y corredores de aire fresco pueden mitigar el efecto urbano de isla térmica o proteger la ciudad de la erosión del suelo. Además, la infraestructura verde proporciona la oportunidad de conectar las zonas urbanas y entornos rurales, generando lugares con potencialidades para vivir y trabajar. La implementación de infraestructuras de soporte de la biodiversidad deben incorporarse a las herramientas de planeamiento urbano y formar parte de las iniciativas de mejora de la calidad de vida y sostenibilidad urbanas (Herrera, 2008). Así, los municipios como agentes públicos responsables de la planificación de la ciudad deben integrar la infraestructura verde como elemento de ordenación urbana. Así, la LOTUP atribuye la planificación y gestión a la administración autonómica y local de forma compartida. A escala local, la red de espacios abiertos se va a convertir en una determinación de ordenación estructural y pormenorizada en el pla- neamiento municipal, y en consecuencia se delimitarán los distintos elementos y se regularán de forma adecuada a sus características, a su funcionalidad y su conectividad (art. 23.2 LOTUP).

La importancia de este instrumento horizontal es que la delimitación de la Infraestructura verde constituye la referencia para estructurar las decisiones de planificación de usos residenciales, dotacionales y económicos, y debe integrarse en todos los sectores de la ciudad. De modo que la regulación de los distintos usos debe hacerse en coherencia con la Infraestructura Verde, para que sus valores naturales y paisajísticos potencien la calidad de vida de la población. En consecuencia, la recuperación del entorno agrario, paisajístico, ecológico e hídrico podría hacerse mediante la delimitación de la Infraestructura Verde del municipio a través de la ordenación estructural del Plan General. En este sentido, el plan de ordenación estructural del municipio va a definir e incorporar los elementos regionales y municipales de la infraestructura verde de manera coordinada con los municipios colindantes, potenciando el carácter espacial de la red.

Pero además, en la ordenación pormenorizada o detallada, el municipio ha de detallar la subinfraestructura verde urbana, que incluirá los espacios no definidos como ordenación estructural y que será objeto de conexión con las zonas verdes, espacios libres e itinerarios peatonales. Así, a escala urbana, la infraestructura verde conecta los espacios libres, jardines y otras dotaciones de la red secundaria, como son los parques urbanos.

\section{LA GESTIÓN URBANISTICA DE LA INFRAESTRUCTURA VERDE}

En el ámbito local, de acuerdo con los documentos europeos, los proyectos de Infraestructura Verde han de ser financiados y apoyados por la administración, de modo que la red ha de ser gestionada, desarrollada y mejorada por la administración. Desde esta perspectiva, la próxima regulación ha previsto un mecanismo de gestión, fomento y financiación urbanística a nivel autonómico, de modo que el art. 77 b) LOTUP ha establecido que "en los sectores 
de planeamiento parcial que, previa evaluación ambiental, se desarrollen excepcionalmente sin estar previstos en el plan general estructural, el porcentaje de aprovechamiento que corresponde a la Administración es del 15\% del aprovechamiento tipo. En este caso un $10 \%$ será para la administración actuante y un 5\% para la Generalitat con la finalidad de destinar los ingresos derivados a la mejora de la Infraestructura Verde". A este respecto, el dictamen del Consell Juridic Consultiu de la Comunidad Valenciana de 7 de febrero de 2014, afirma que la operatividad del precepto será bastante reducida, en la medida que comprende espacios de dominio público estatal y de propiedad particular, lo que puede obstaculizar las actuaciones de la administración autonómica en la mejora de la infraestructura verde. Por otro lado, se recomienda que la cesión urbanística se produzca a favor de la administración actuante, sin perjuicio de la cesión de suelo posterior de carácter finalista a la Infraestructura verde, cuyos espacios no serán aptos para la prestación de servicios públicos autonómicos. Por otro lado, la gestión municipal de la infraestructura verde se realizará mediante la gestión del patrimonio público del suelo (art. 98.1 e) LOTUP), pues sus bienes y recursos pueden ser destinados a la conservación y mejora de la infraestructura verde, del entorno urbano y protección del paisaje.

Sin embargo, como advierte el Comité Económico y Social Europeo (Dictamen 2014/C 67/31), la infraestructura verde no es sólo responsabilidad de los municipios, para su eficacia han de involucrarse en su mantenimiento y mejora los promotores privados de infraestructuras, empresas, constructores, organizaciones medioambientales, y los ciudadanos. Los particulares han de tener un papel fundamental en procesos participativos de planificación urbanística y la implicación de las empresas y promotores de infraestructuras, constructores, agricultores o asociaciones resulta crucial para el desarrollo de proyectos de infraestructura verde mediante la participación activa de la sociedad civil. Por ello, creo necesario que el proyecto de ley valenciana debe incluir el reconocimiento de los particulares y el carácter indispensable de la inversión privada en el desarrollo de las actuaciones sobre la infraestructura verde, pues son los principales beneficiarios de las soluciones naturales que aporta.

\section{ACCIONES PÚBLICAS DIRECTAS EN MATERIA DE PAISAJE Y CONSERVACIÓN DEL MEDIO NATURAL}

Las administraciones territoriales adoptan una visión paisajística del espacio en la que integran los factores naturales en el planeamiento territorial y urbanístico con acciones de protección, gestión, conservación y regeneración. Además de preservar los recursos culturales, naturales y visuales, se crean iniciativas públicas para crear espacios de ocio y esparcimiento que impidan la fragmentación de los ecosistemas naturales y agrícolas, y que favorezcan la transformación de las barreras urbanas entorno a los espacios naturales mejorando la accesibilidad al paisaje. Así, merece la pena destacar diversas acciones y proyectos que coadyuvan en el modelo de ciudad contemporánea en la que se conecta el sistema de espacios abiertos a escala regional con el incremento de parques y espacios verdes ya que permiten equilibrar los déficits ambientales de la ciudad, además de complementar su oferta recreativa.

Un ejemplo para preservar la diversidad de los paisajes es la Infraestructura Verde del Área Metropolitana de Valencia: Corredor del Rio Turia, Huerta, Albufera y Mar Mediterráneo (Figura $3)$, que supone un gran espacio verde entre ocho municipios que bordean el río, eje vertebrador del área metropolitana. Con esta actuación, se pretende evitar la fragmentación de los ecosistemas naturales y agrícolas y las barreras urbanas alrededor del

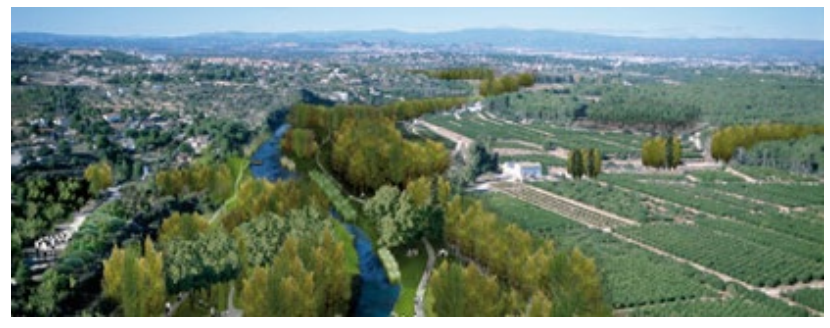

Figura 3. Infraestructura Verde del área metropolitana de Valencia: rio Túria 
río, mejorando el acceso al paisaje. Otra actuación propuesta con el mismo objetivo es el Gran Parque Metropolitano de Alicante: Corredor Rio Monnegre-Serpis. También en la Comunidad Valenciana, y desde una perspectiva estética se inician planes de protección y ordenación de las vistas hacia el paisaje como el Plan de mejora visual de los accesos a los municipios y el plan de protección y ordenación de las vistas desde las vías de comunicación.

En España, entre otras iniciativas de infraestructura local destaca el anillo verde de Vitoria (Figura 4) que compone un área sostenible que proporciona servicios ecosistémicos y conecta las áreas urbanas, periurbanas, y los elementos artificiales. Entre sus efectos, se ha constatado que la infraestructura verde consigue enfriar el clima urbano en verano y reducir la contaminación del suelo, y junto a estos efectos, se invierte en educación ambiental, tecnología, innovación y proyectos de revitalización urbana en zonas degradadas. No obstante, también se desarrollan proyectos de infraestructura verde a escala de la UE como el "Cinturón verde europeo" (Figura 5), del Mar de Barens al Mar Negro, el Rin y el Danubio o los bosques fenoescandinavos (Figura 6), los cuales generan ventajas al garantizar la resilencia y vitalidad de algunos ecosistemas más representativos de Europa.

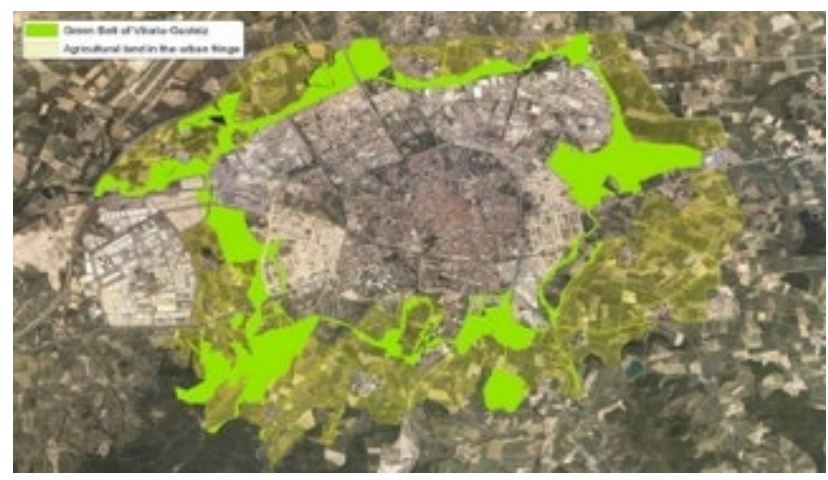

Figura 4. Anillo Verde de Vitoria.

(htpp: www.Urban360.me)

Igualmente, se encuentran experiencias en EEUU donde se desarrollan programas de infraestructura verde en ciudades como Florida (Figura 7), Washington, Philadelphia (Figura 8) o Nueva York (Figuras 9 y 10) tratan este problema, y se ayudan

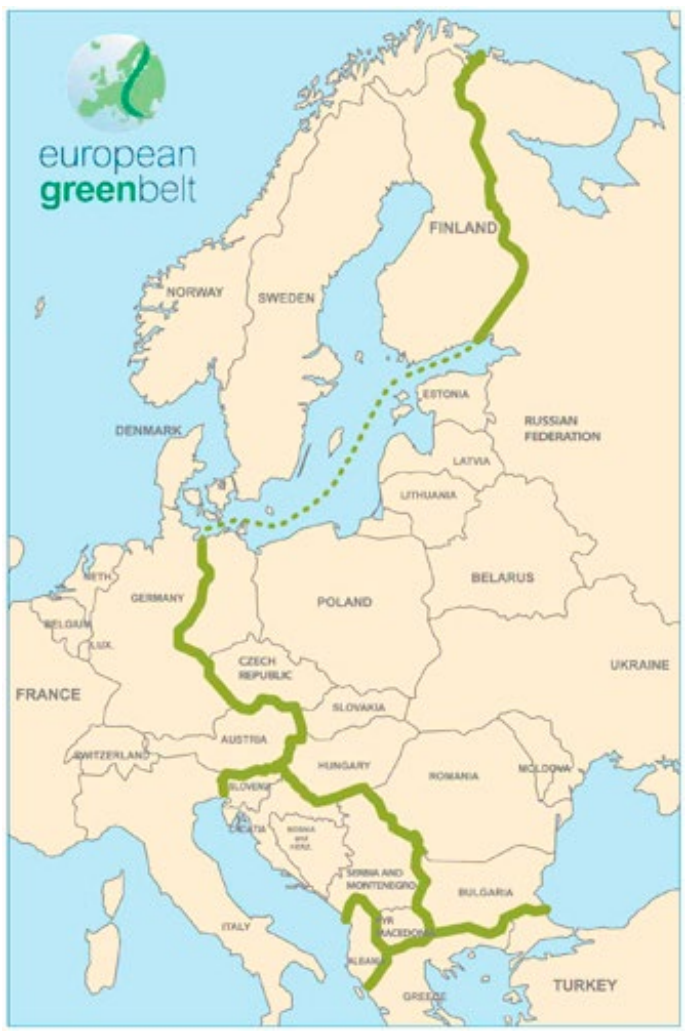

"Cinturón verde europeo"

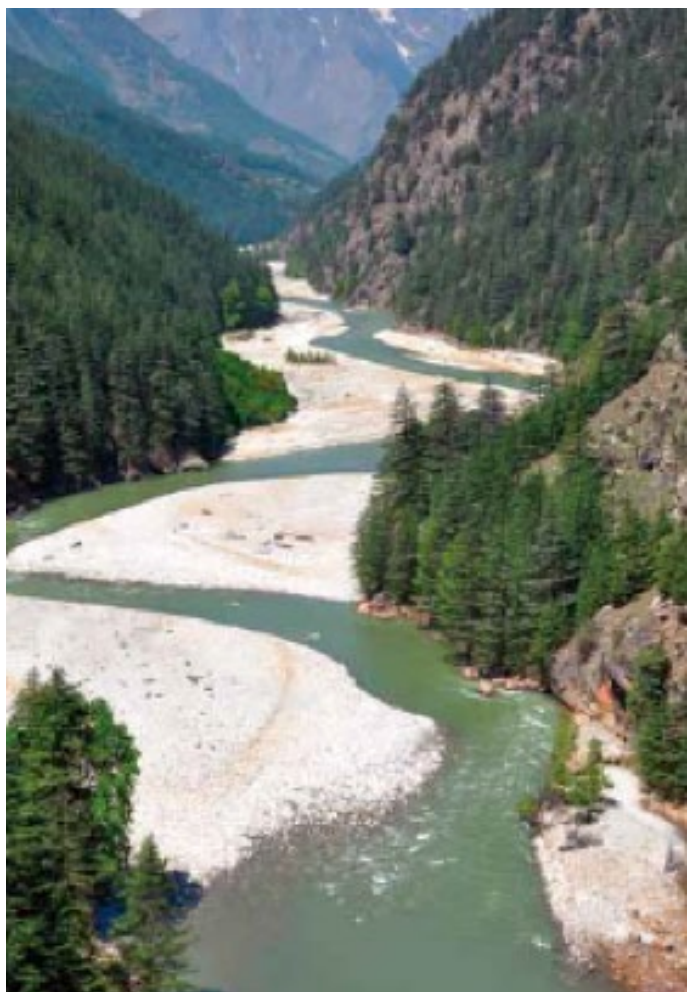

Bosques escandinavos

Figura 5 y 6. IV Europa. Brochure "Building a Green Infraestructure for Europe”.European Commission 


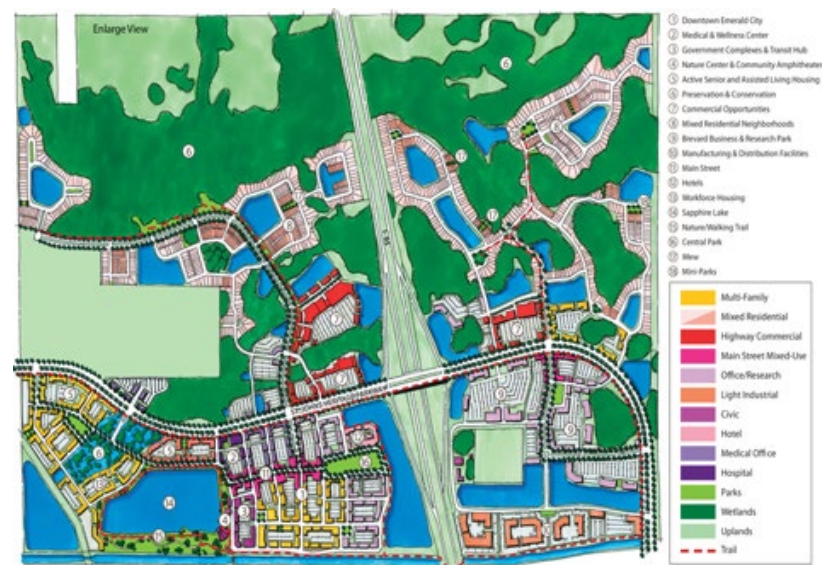

Figura 7. IV Florida. Htpp: //www.emeraldatycityflorida.com

de la fijación de la vegetación para conseguir una mejora de la calidad del aire, agua, biodiversidad, y de oferta de empleo a la población. (http://water. epa.gov/infrastructure/greeninfrastructure/index. cfm\#Policies_and_Plans. A nivel mundial, vid: http://www.teebweb.org).

\section{CONCLUSIONES}

Resulta esencial comprender que la Infraestructura Verde se configura como una subestructura, red o sistema natural que se vincula necesariamente al mantenimiento y desarrollo de la población en el territorio y que presta una serie de servicios ecosistémicos (AEMA, 2011), es decir, aporta una ventajas ambientales, sociales y económicas en las áreas urbanas, en el entorno rural, y en la ordenación territorial. Así como se necesita mejorar y ampliar la infraestructura construida también es necesario mejorar y ampliar la infraestructura verde de espacios protegidos, bosques, áreas agrícolas, paisajes de alto valor, hábitats, parques y áreas naturales que sustentan el aire limpio, el agua y los recursos naturales en el territorio.

Esta figura se introduce en la legislación de ordenación del territorio como un enfoque estratégico para la planificación y gestión del territorio a escala regional y local, en la que idealmente, la planificación y diseño de la misma ha de ser previa a la ordenación de los usos que se desarrollan en el territorio. En este sentido, la legislación valenciana adopta la concepción previa y multifuncional de la infraestructura verde en la planificación territorial y urbanística conforme a los criterios de la Estrategia de la Unión Europea de 2013 y la Agenda Territorial Europea 2020, y además, atribuye a la administración autonómica y local la responsabilidad de la mejora y conservación de la red interconectada de espacios a través de un mecanismo de financiación público. A este respecto, se aleja de los planteamientos comunitarios y de la experiencia norteamericana en la que participan agentes públicos y privados,

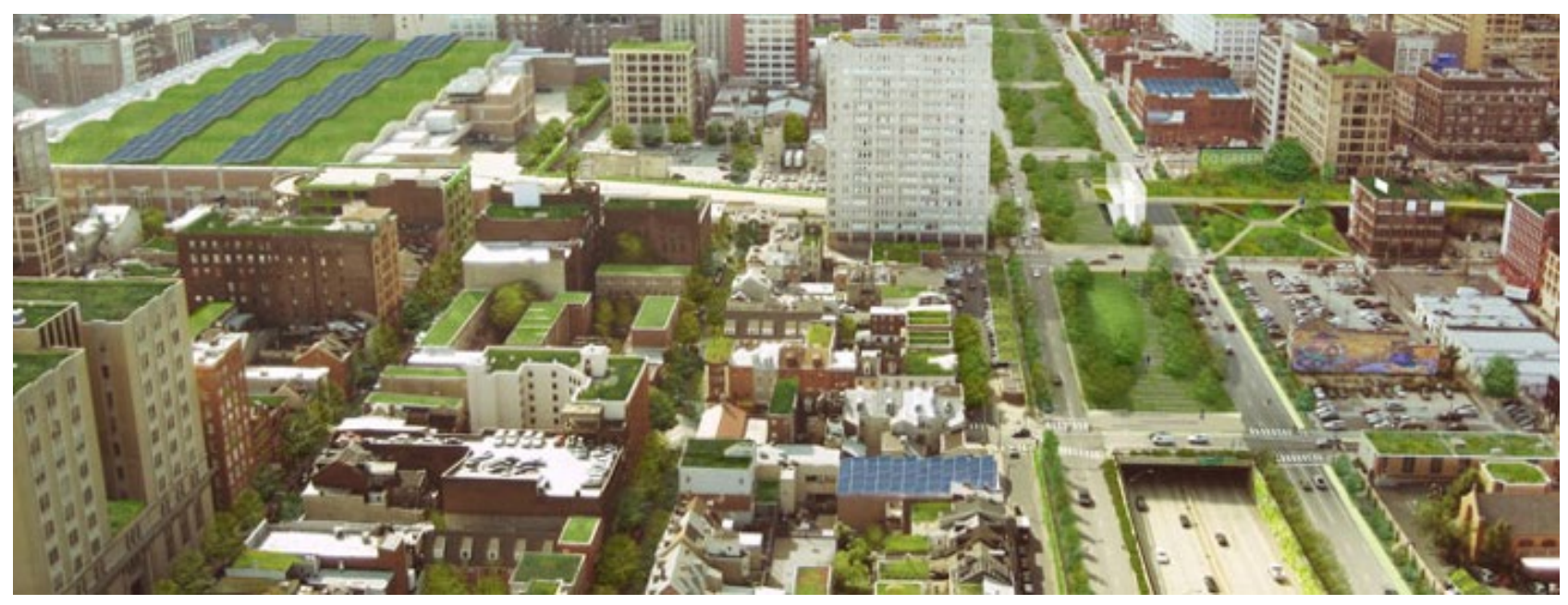

Figura 8. IV Philadelphia. Htpp://www. Philywatersheds.org 

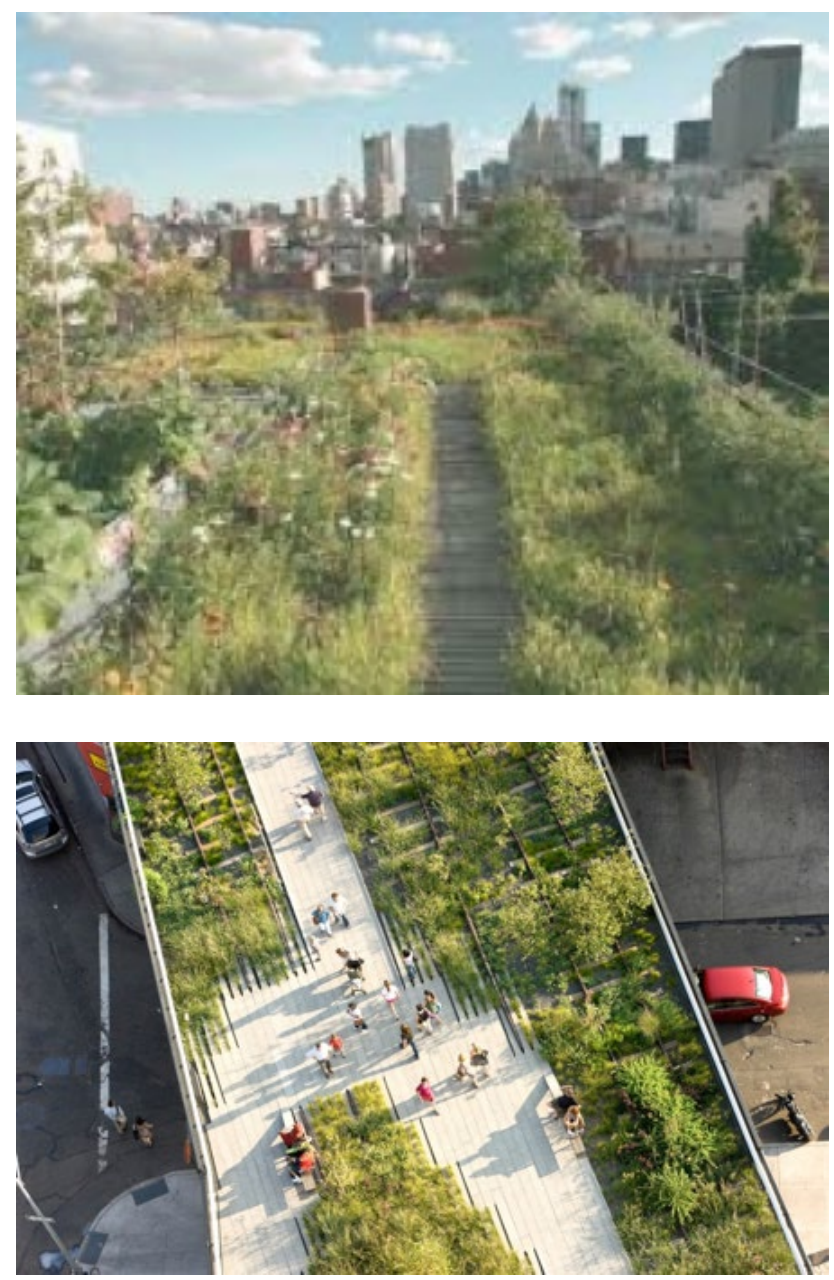

Figuras 9 y 10. Infraestructura Verde de New York: http://www.nyc.gov/html/dep/html/stormwater/ nyc_green_infrastructure_plan.shtm2010 Green Infraestructure Plan New York.

pues para alcanzar su éxito resulta fundamental el concurso de investigadores, planificadores, expertos de la arquitectura del paisaje, promotores de proyectos de infraestructuras, agricultores, constructores, y otros agentes privados de forma conjunta con la acción pública.

Finalmente, hay que advertir que junto a las ventajas señaladas hay que tener en consideración potenciales limitaciones como la identificación de externalidades negativas para espacios verdes urbanos (especies invasoras de plantas ornamentales, propagación de los alérgenos o toxinas en las plantas, los animales de vida silvestre que transmiten enfermedades, daños a la infraestructura construida por descomposición o raíces de los árboles, el agotamiento de los recursos hídricos debido a la riego, el escurrimiento de nutrientes o la propagación de contaminantes a través del suelo y material vegetal). En general, la ponderación entre las externalidades positivas y negativas de la infraestructura en base al criterio coste-beneficio ha de introducirse en el proceso de toma de decisiones por los agentes públicos responsables en la planificación, mejora y conservación de la infraestructura verde. A partir de la entrada en vigor de la LOTUP, el éxito de este enfoque estará limitado por el verdadero potencial de la infraestructura verde urbana y por la participación pública en el procedimiento de planificación y gestión.

\section{REFERENCIAS}

Agencia Territorial de la Unión Europea 2020: Hacia una sociedad integradora, inteligente y sostenible para una Europa de Regiones diversas, de 18 de mayo de 2011, Hungria.

Benedict, M.A., \& Mcmahon, E.T. 2002. Green infrastructure: smart conservation for the 21st century, Washington, DC, Sprawl watch clearing House, May 2002. Online en http://sprawlwatch.org/greeninfraestructure.pdf

Firehock, K. 2010. A short History or the term Green Infraestructure and Selected Literature, online en http://www. gicinc.org/PDFs/GI\%20History.pdf

Comunicación de la Comisión al Parlamento Europeo, al Consejo, al Comité Económico y Social Europeo, y al Comité de las Regiones. Estrategia de la UE sobre la biodiversidad hasta 2020: nuestro seguro de vida y capital natural. COM (2011) 244 final. Bruselas, 3.05.2011

Comunicación de la Comisión al Parlamento Europeo, al Consejo, al Comité Económico y Social Europeo, y al Comité de las Regiones. Infraestructura Verde: mejora del capital natural de Europa. DCOM (2013) 249 final. Bruselas 6.05.2013

Dictamen del Comité Económico y Social Europeo sobre la Comunicación de la Comisión al Parlamento Europeo, al Consejo, al Comité Económico y Social Europeo, y al Comité de las Regiones- Infraestructura Verde: mejora del capital natural de Europa”. DOCE C 67 de 6.03.2014. 
Fernández Rodriguez, C. 2007. El estreno de nuestro derecho en la ordenación paisajística: a propósito de la ordenación y protección del paisaje en la legislación valenciana, $R A P$, núm. 172, pp. 363-401.

Fernández Rodriguez, C. 2013. Estética y paisaje urbano. La intervención administrativa en la estética de la ciudad, La ley, Madrid.

Herrera Calvo, P.M. "Infraestructuras de soporte de la Biodiversidad: planificando el ecosistema urbano", Ciudades, 11, 2008, pp. 167-188.
Informe de la Agencia Europea del Medio Ambiente. 2011. Green Infraestructure and territorial cohesion.

Taylor, S \& Taylor, J.R. 2013. Supplying urban ecosystem service through multifunctional green infrastructure in the United States. Landscape ecology in review, 28: 1447-1463. 